American Journal of Pharmaceutical Education 2017; 81 (2) Article 30.

\title{
RESEARCH
}

\section{Pharmacy Educators' Knowledge of Medication Safety and Their Perception Toward Its Integration into the Doctor of Pharmacy Curriculum in Saudi Arabia}

\author{
Abdulmalik M. Alkatheri, PharmD, ${ }^{\mathrm{a}, \mathrm{b}}$ Rami Bustami, PhD, ${ }^{\mathrm{a}}$ Abdulkareem M. Albekairy, PharmD, MSc, ${ }^{\mathrm{a}, \mathrm{b}}$ \\ Hind Almodaimegh, PharmD, ${ }^{\mathrm{a}, \mathrm{b}}$ Sahar Alghamdi, BSPharm, ${ }^{\mathrm{a}}$ Shemylan Alharbi, PharmD, ${ }^{\mathrm{a}, \mathrm{b}}$ \\ Nabil Khalidi, PharmD, ${ }^{a}$ John E. Murphy, PharmD, ${ }^{c}$ Amjad M. Qandil, PhD ${ }^{\text {a,d }}$ \\ ${ }^{a}$ King Saud bin Abdulaziz University for Health Sciences and King Abdullah International Medical Research Center, \\ Ministry of National Guard Health Affairs, Riyadh, Saudi Arabia \\ ${ }^{\mathrm{b}}$ King Abdulaziz Medical City, Ministry of National Guard Health Affairs, Riyadh, Saudi Arabia \\ ${ }^{c}$ University of Arizona, Tucson, Arizona \\ d Jordan University of Science and Technology, Irbid, Jordan \\ Submitted October 6, 2015; accepted March 29, 2016; published March 25, 2017.
}

Objective. To assess pharmacy educators' knowledge of medication safety and their perception toward its integration into the PharmD curriculum in Saudi Arabia.

Methods. A survey was administered to pharmacy educators at a college of pharmacy and its affiliate hospital. Knowledge, training, and perception toward integrating medication safety into the PharmD curriculum were evaluated.

Results. More than $50 \%$ of respondents indicated that medication safety should be covered within selected courses, and $65 \%$ indicated that such courses should be mandatory. Pharmacy practice educators had significantly higher levels of knowledge about medication safety than their nonpractice counterparts. Perceptions toward medication safety integration into the curriculum varied significantly by general discipline, academic degree, years of experience, and gender.

Conclusion. Pharmacy educators in Saudi Arabia understand the importance of medication safety and its integration into the curriculum. Further studies are needed to guide curricular change to achieve this integration.

Keywords: patient safety, pharmacy education, doctor of pharmacy curriculum, medication safety

\section{INTRODUCTION}

With the increasing dependence on medication therapy as the basic intervention for most diseases, patients receiving medications are more susceptible than ever to potential harm, which can result from adverse drug events (ADEs) as well as medication errors. According to reports from the Institute of Medicine (IOM), medication-related errors are a significant cause of morbidity and mortality in the United States, accounting for one of every 131 outpatient

Corresponding Authors: Amjad M. Qandil, Pharmaceutical Sciences Department, College of Pharmacy, King Saud bin Abdulaziz University for Health Sciences, Riyadh 11481, Kingdom of Saudi Arabia. Tel: +966-11-4295007. Fax: +966-11-4295059. E-mail: qandila@ksau-hs.edu.sa. Abdulmalik M. Alkatheri, Pharmacy Practice Department, College of Pharmacy, King Saud bin Abdulaziz University for Health Sciences, Riyadh 11481, Kingdom of Saudi Arabia. Tel: +966-11-4295005. Fax: +966-11-4295057. E-mail: katheria@ngha.med.sa deaths and one out of 854 inpatient deaths. ${ }^{1,2}$ A recent report by the Centers for Disease Control and Prevention (CDC) estimated that in the United States, more than 700,000 people are admitted annually into hospital emergency departments for ADEs; about $20 \%$ of these patients are admitted to the hospital for additional treatment. ${ }^{3}$ While this is a significant patient safety problem that is associated with increased patient morbidity and mortality, most of these ADEs can be avoided. ${ }^{1,4}$ Other reports have emphasized the importance of reducing or eliminating medication errors through enhancing communication with patients, continuously checking for errors, and supplying clinicians and medical educators with all the information and tools they need to boost their knowledge about medication safety and quality. ${ }^{1,2}$

Certain factors may contribute to increased risk of medication errors in the pharmacy profession, including pharmacy educators' lack of adequate knowledge about medication safety and subsequent limited teaching of the 


\section{American Journal of Pharmaceutical Education 2017; 81 (2) Article 30.}

content to students. Pharmacy educators who are clinicians can help reduce the risk of harm from medications with improved learning about medication safety and strategies to reduce medication errors, which is crucial to enhancing general safety and quality in health care. ${ }^{5}$ Increased knowledge of these issues and practice of safety techniques by clinical faculty members can then help them to personally participate in safety measures as well as enhance their ability to provide educational content in these areas to others and serve as role models to students during clerkships. Nonclinical basic science faculty members, whether pharmacists or not, can participate in the education of students about medication safety principles if they are sufficiently knowledgeable in the area.

Medication safety training literature continues to acknowledge the significant contribution health professions faculty members make regarding advancing patient safety and the development of safer practitioners. In this regard, the World Health Organization (WHO) advocates the implementation of patient safety concepts into the curricula of medical schools. ${ }^{6}$ The American Association of Colleges of Pharmacy (AACP) and the Accreditation Council for Pharmacy Education (ACPE) have also recognized the importance of patient safety and quality improvement knowledge for future pharmacists and encourage pharmacy schools to add these topics to their doctor of pharmacy (PharmD) curricula. ${ }^{7}$ The ACPE standards 2016 has embedded medication safety in Standard 2 and clearly stated that safety topics should be a part of many of the required basic clinical elements of the didactic PharmD curriculum. ${ }^{8}$ From another angle, there is a growing body of research focusing on pharmacy educators' knowledge and perception toward the integration of medication safety into the undergraduate and postgraduate pharmacy college curricula. Several studies have assessed the mode and level at which the topic of medication errors is included in the curricula of schools of pharmacy in the United States. ${ }^{9}$ Other studies focused on the science of safety (SoS) curriculum in US colleges and schools of pharmacy as well as contrasting pharmacy faculty perceptions in the United States and other countries on science of safety experiential education in the curricula for pharmacy students by conducting interviews and Internet-based surveys. ${ }^{10}$ Most of these studies addressed the knowledge and attitudes of pharmacy educators toward the integration of medication safety-related topics into pharmacy education in the United States. Furthermore, a study by Johnson and colleagues, which was instrumental in designing this current investigation, concluded that PharmD curricula should include a "meaningful and consistent" medication safety instruction. $^{11}$
Pharmacy practice and education in the Middle East, particularly in Arabic-speaking countries, continues to advance. While there have been some general reports addressing the importance of medication safety in the medical practice in these countries, none of these studies assessed pharmacy educators' knowledge and perceptions toward the integration of medication safety into pharmacy education in this region. ${ }^{12-15}$ This is an area for further research for which pharmacy educators have distinctive expertise and are uniquely positioned to play an instrumental role. Therefore, this cross-sectional survey was designed to assess pharmacy educators' knowledge about medication safety and their attitudes toward its integration into the PharmD curriculum at King Saud bin Abdulaziz University for Health Sciences (KSAU-HS) College of Pharmacy. The two primary purposes of this study were to evaluate pharmacy faculty members' knowledge on medication safety-related topics, and to determine their attitudes toward whether, when, where, and how medication safety topics should be integrated into the curriculum.

\section{METHODS}

A comprehensive questionnaire was developed and administered as a survey to all 43 full- and part-time pharmacy faculty educators at the KSAU-HS College of Pharmacy in Riyadh, Saudi Arabia, an institution that is affiliated with the Ministry of National Guard Health Affairs and its hospitals and clinics in Saudi Arabia. This study was approved by the college's research committee and ethics subcommittee. The questionnaire consisted of three major sections: 1) questions that collected information on demographic characteristics of respondents including gender, general and specific discipline, academic degree, rank, and years of experience in pharmacy education; 2) respondents' knowledge about medication error concepts and types of medication errors that occur; and 3) attitudes of respondents regarding whether, when, where, and how medication safety topics should be integrated into the PharmD curriculum. The design of the questionnaire was partially guided by the study of Johnson and colleagues. ${ }^{11}$

Six medication safety and error concepts (domains) were listed in the questionnaire: human error, medical errors, medication errors, quality improvement, error reporting, and near-miss analysis/reporting. The questionnaire also included items focused on the following five medication safety/error types: high-alert medications, look-alike sound-alike, do not crush, prohibited abbreviations, and drug allergies.

Face validity of the survey questionnaire was assessed by an expert panel that was independent to the panel that established the survey questions. Construct 


\section{American Journal of Pharmaceutical Education 2017; 81 (2) Article 30.}

validity was also assessed using Cronbach's alpha and determined as indicated by the relatively high value of the Cronbach's alpha measure of internal consistency $(\alpha=.75)$.

Responses to questions reflecting knowledge were ranked on a five-point Likert-type scale on which $1=$ none and $5=$ excellent, with the higher scores indicating better knowledge. Total scores for knowledge and perception were calculated by adding scores for individual types or domains of medication errors.

Descriptive statistical analyses were initially performed for the study sample. Continuous variables were summarized using median and range. Proportions were used for categorical variables. Total scores for knowledge, training, and perception regarding incorporation of the medication safety topics into the PharmD curriculum were evaluated and compared with educators' demographic factors including gender, general discipline, specific discipline, academic degree, academic rank, and years of experience in pharmacy education. Categorical data were analyzed using the chi-square test. The distribution of all continuous data was examined. For continuous variables with distributions that approximated normality, a $t$ test or one-way analysis of variance (ANOVA) was used for comparisons. When normality assumptions were not satisfied, the nonparametric Mann-Whitney U test or Kruskal-Wallis test were used. Statistical significance was set at $p<.05$. All statistical analyses were performed using SPSS 21.0 (IBM Corp., Armonk, NY).

\section{RESULTS}

Thirty-nine (90\%) of 43 full- and part-time faculty members responded. Descriptive statistics of the respondents are displayed in Table 1. Most faculty members were in pharmacy practice with the bulk holding joint appointments with the college and health system. All of the basic pharmaceutical sciences educators held pharmacy degrees in addition to their graduate work. Graduate areas included pharmaceutics and pharmacology. Only one participant had a full-time faculty appointment in pharmacy practice. Terminal academic degrees were primarily at the MS, $\mathrm{PhD}$, and PharmD levels (62\%); the remaining $38 \%$ of respondents held bachelor degrees. Most (59\%) of the respondents held no academic rank at the college, and the majority of the faculty members were experienced educators with six or more years of academic experience (59\%).

The results in Table 2 showed that the total score reflecting theoretical knowledge of the concepts of medication errors from all error domains was significantly or marginally different by general discipline and gender;
Table 1. Descriptive Statistics for the Pharmacy Educators who Participated in the Study $(\mathrm{N}=39)$

\begin{tabular}{lc}
\hline & No. (\%) \\
\hline Gender & \\
Female & $14(36)$ \\
Male & $25(64)$ \\
General discipline & \\
Basic sciences & $6(15)$ \\
Pharmacy practice & $33(85)$ \\
Specific discipline & \\
Pharmacy practice joint appointment & $32(82)$ \\
Pharmaceutics & $4(10)$ \\
Pharmacology & $2(5)$ \\
Pharmacy practice - full time & $1(3)$ \\
Academic degree & \\
PhD & $6(15)$ \\
PharmD & $10(26)$ \\
MSc & $8(21)$ \\
BSc & $15(38)$ \\
Academic rank & \\
Professor or associate professor & $3(8)$ \\
Assistant professor & $7(18)$ \\
Lecturer & $6(15)$ \\
Other & \\
Years of experience in pharmacy education & $23(59)$ \\
1-5 & \\
6-10 & $16(41)$ \\
$11+$ & $14(36)$ \\
\hline
\end{tabular}

${ }^{\mathrm{a} N o n f a c u l t y ~ p r o f e s s i o n a l s ~ i n c l u d i n g ~ h o s p i t a l ~ p h a r m a c i s t s, ~ c o n s u l-~}$ tants, and other experienced professionals

participants in the pharmacy practice discipline and male participants had better theoretical knowledge than the basic sciences discipline and females, respectively.

The total score reflecting ratings of personal practical knowledge of the concepts of medication errors from all error domains was significantly or marginally different by general discipline, academic degree, and academic rank; participants in the pharmacy practice discipline and those with PharmD, MSc, or BSc degrees also had significantly better practical knowledge (compared to those with a $\mathrm{PhD}$ ).

The results in Table 2 also indicate that respondents' practical knowledge of the types of medication error differed significantly or marginally by gender, general discipline, academic degree, and years of experience in pharmacy education; female participants, participants in the pharmacy practice discipline, those with PharmD, $\mathrm{MSc}$, or BSc degrees (compared to $\mathrm{PhD}$ ), as well as those with increased years of experience in pharmacy education, rated themselves as having better practical knowledge of types of medication errors. A trend toward higher self-rated theoretical knowledge about medication error domains and 


\section{American Journal of Pharmaceutical Education 2017; 81 (2) Article 30.}

Table 2. Pharmacy Educators' Theoretical and Practical Knowledge of Medication Safety/Error Categorized by Demographics $(\mathrm{N}=39)$

\begin{tabular}{|c|c|c|c|c|}
\hline & Possible Range & Actual Range & Median & $p$ value $^{\mathrm{a}}$ \\
\hline \multicolumn{5}{|c|}{ Theoretical knowledge of concepts of medication errors } \\
\hline General discipline & & & & .043 \\
\hline Basic sciences & $6-30$ & $14-24$ & 17 & \\
\hline Pharmacy practice & $6-30$ & $6-30$ & 24 & \\
\hline Gender & & & & .076 \\
\hline Female & $6-30$ & $6-30$ & 20 & \\
\hline Male & $6-30$ & $13-30$ & 24 & \\
\hline \multicolumn{5}{|c|}{ Practical knowledge of concept of medication errors } \\
\hline General discipline & & & & $<0.001$ \\
\hline Basic sciences & $6-30$ & $14-24$ & 17 & \\
\hline Pharmacy practice & $6-30$ & $6-30$ & 24 & \\
\hline Academic degree & & & & .004 \\
\hline $\mathrm{PhD}$ & $6-30$ & $6-22$ & 18.5 & \\
\hline PharmD & $6-30$ & $20-30$ & 25 & \\
\hline MSc & $6-30$ & $15-30$ & 27 & \\
\hline BSc & $6-30$ & $23-30$ & 27 & \\
\hline \multicolumn{5}{|l|}{ Practical knowledge of types of medication errors } \\
\hline General discipline & & & & $<.001$ \\
\hline Basic sciences & $5-25$ & $5-22$ & 19 & \\
\hline Pharmacy practice & $5-25$ & $16-25$ & 25 & \\
\hline Gender & & & & .035 \\
\hline Female & $5-25$ & $20-25$ & 25 & \\
\hline Male & $5-25$ & $5-25$ & 22 & \\
\hline Academic degree & & & & .014 \\
\hline $\mathrm{PhD}$ & $5-25$ & $5-22$ & 19 & \\
\hline PharmD & $5-25$ & $20-25$ & 24 & \\
\hline MSc & $5-25$ & $18-25$ & 25 & \\
\hline BSc & $5-25$ & $16-25$ & 25 & \\
\hline Experience in pharmacy education, years & & & & .029 \\
\hline $1-5$ & $5-25$ & $18-25$ & 22.5 & \\
\hline $6-10$ & $5-25$ & $5-25$ & 25 & \\
\hline $11+$ & $5-25$ & $15-25$ & 22 & \\
\hline
\end{tabular}

${ }^{a}$ Based on the Mann-Whitney U test or the Kruskal-Wallis test

types was seen among PharmD participants compared to all other degrees combined. Median (range) score was 25 (17-30) for respondents with a PharmD vs 21 (6-30) for respondents with other degrees $(p=.085$, and 23.5 [18-25] for PharmD vs 20 [9-25] for all other degrees, $p=.092$, respectively).

The results in Table 3 showed that the proportion of participants with previous training in any of the medication/ safety error domains was marginally different by general discipline and years of experience in pharmacy education. Results also showed that the proportion of participants reporting instructor/trainer involvement in college curriculum was significantly or marginally different by academic degree, academic rank, and gender.

Responses to questions regarding educators' attitudes toward the incorporation of medication safety content into the PharmD curriculum indicated that the majority of respondents believed that medication error domains should be covered: human error, $86 \%$; medical errors, $97 \%$, medication errors, $100 \%$; quality improvement, $95 \%$; error reporting, 92\%; and near miss, $89 \%$. The majority also indicated that courses covering medication safety domains should be mandatory: human error, 69\%; medical errors, $72 \%$; medication errors, $92 \%$; quality improvement, $82 \%$; error reporting, $85 \%$; and near miss, $77 \%$. About $38 \%$ to $54 \%$ of participants indicated that the third and fourth professional years are the best educational years to cover each of the medication error domains in the curriculum. Most respondents thought the domains should be covered in selected courses, while approximately one-third favored a longitudinal approach (Figure 1).

Almost all (95\% to 97\%) participants agreed that all medication error types should be covered in the curriculum. From $26 \%$ to $40 \%$ said that professional years 1 


\section{American Journal of Pharmaceutical Education 2017; 81 (2) Article 30.}

Table 3. Pharmacy Educators' Training in Medication Safety/ Error Categorized by Demographics

\begin{tabular}{|c|c|c|c|c|}
\hline & Total & $\mathbf{N}$ & Percent & $\begin{array}{c}p \\
\text { value }^{\text {a }}\end{array}$ \\
\hline \multicolumn{5}{|c|}{$\begin{array}{l}\text { Previous training in medication/ } \\
\text { safety error domains }\end{array}$} \\
\hline General discipline & & & & .089 \\
\hline Basic sciences & 6 & 3 & 50 & \\
\hline Pharmacy practice & 33 & 27 & 82 & \\
\hline $\begin{array}{c}\text { Years of experience in } \\
\text { pharmacy education }\end{array}$ & & & & .090 \\
\hline $1-5$ & 16 & 14 & 88 & \\
\hline $6-10$ & 14 & 8 & 57 & \\
\hline $11+$ & 9 & 8 & 89 & \\
\hline \multicolumn{5}{|c|}{$\begin{array}{l}\text { Instructor/trainer Involvement in } \\
\text { college curriculum }\end{array}$} \\
\hline Gender & & & & .034 \\
\hline Female & 14 & 0 & 0 & \\
\hline Male & 25 & 8 & 32 & \\
\hline Academic degree & & & & .075 \\
\hline $\mathrm{PhD}$ & 6 & 2 & 33 & \\
\hline PharmD & 10 & 4 & 40 & \\
\hline $\mathrm{MSc}$ & 8 & 2 & 25 & \\
\hline $\mathrm{BSc}$ & 15 & 0 & 0 & \\
\hline Academic rank & & & & .002 \\
\hline $\begin{array}{l}\text { Professor or associate } \\
\text { professor }\end{array}$ & 3 & 1 & 33 & \\
\hline Assistant professor & 7 & 5 & 71 & \\
\hline Lecturer & 6 & 0 & 0 & \\
\hline Other $^{\mathrm{b}}$ & 23 & 2 & 9 & \\
\hline
\end{tabular}

a Based on the chi-square test or Fisher's exact test

${ }^{\mathrm{b}}$ Nonfaculty professionals including hospital pharmacists, consul-

tants, and other experienced professionals

through 4 were the best educational levels at which medication errors should be covered. Also, 30\% to 39\% of respondents believed that pharmacy practice was the part of the curriculum in which medication error types should be taught, while about $30 \%$ indicated that medication error types should be taught in all parts of the curriculum. As for medication error domains, the vast majority of participants agreed that courses covering medication error types should be mandatory; high alert medications, 92\%; look-alike sound-alike, 90\%; do not crush, $85 \%$; prohibited abbreviations, $87 \%$; and drug allergies, 95\%. Figure 2 shows how respondents thought the types of errors should be delivered. As with the domains, most thought the topics should be covered in selected courses and approximately one-third favored a longitudinal approach for the various topics.

\section{DISCUSSION}

This study explored pharmacy educators' perceived knowledge of medication safety domains and topics and their perspectives on its integration into the PharmD curriculum at KSAU-HS College of Pharmacy. There were three key findings from this research. First, the total selfrating score reflecting theoretical knowledge of the concepts of medication errors from all error domains was significantly higher among educators in the pharmacy practice discipline. Also, participants in the practice discipline and those with a PharmD, master's, or undergraduate degree had better practical knowledge compared to $\mathrm{PhD}$ holders, even though all respondents had a pharmacy degree. Similarly, self-rated practical knowledge about types of medication errors was significantly better among educators in the pharmacy practice discipline. These results are not surprising given the differences in nature and focus between these disciplines. Participants in the practice discipline and those holding a PharmD degree are more likely to have been exposed to or practice in a clinical setting, thus gaining a higher level of knowledge about medication safety. It might also be expected that those with PharmD degrees would have higher self-ratings about the domains and types of medication errors as these are required components of the PharmD curriculum in most programs, at least in the last 10 or so years. In previous surveys on the perspectives of faculty members engaged in pharmacy education, most participants raised concerns about the extent to which faculty members are adequately prepared to teach and mentor in the area of medication safety. ${ }^{4,16}$

The above results imply the need to offer more interdisciplinary training for academic faculty educators to develop a better level of knowledge about medication safety domains and topics. The variations in knowledge about medication safety at KSAU-HS College of Pharmacy triggered the implementation of a comprehensive policy that made it mandatory that faculty members and practitioners be medication safety-certified to ensure their knowledge and training. This policy is directed toward faculty members of all disciplines including those with a "nonpractice" focus such as pharmaceutical sciences. Some in other countries and in other professions have already initiated the development of patient safety didactic structures for education and outcomes. ${ }^{16-18}$

The findings also demonstrated that the vast majority of educators $(>65 \%)$ believe that courses covering medication safety domains should be mandatory. These results are similar to those obtained from previous studies on the integration of science of safety topics in the curriculum of pharmacy colleges in the United States. ${ }^{19,20}$ Approximately $65 \%$ of US pharmacy schools and colleges surveyed indicated that they covered science of safety (SoS) topics and the majority of these believed they were allocating sufficient time to this area of the 


\section{American Journal of Pharmaceutical Education 2017; 81 (2) Article 30.}

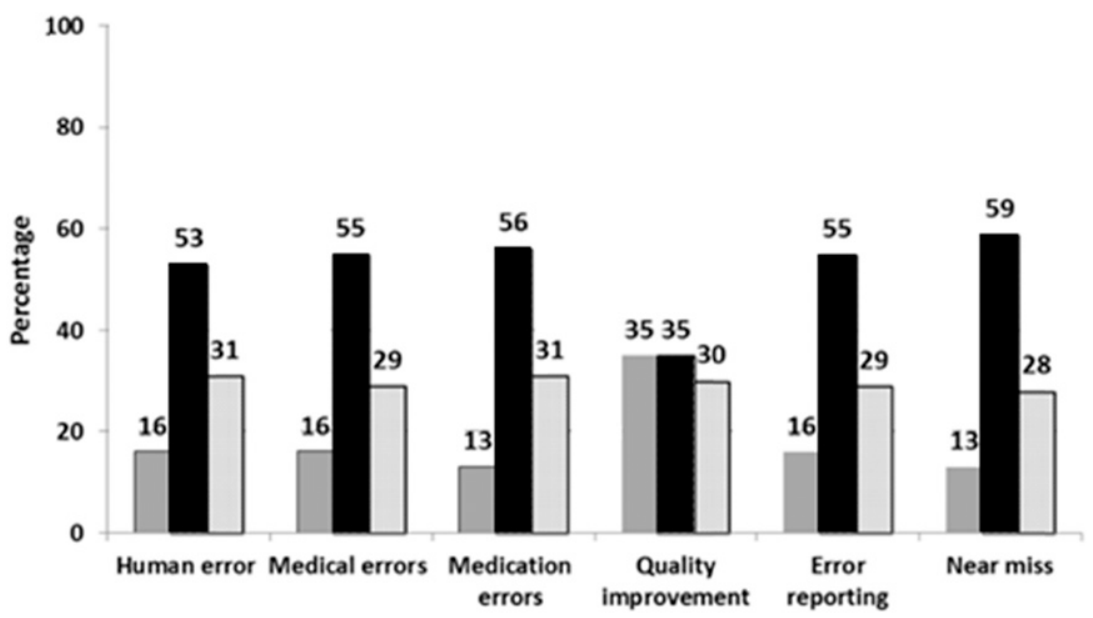

Figure 1. Percentage of pharmacy educators indicating how medication safety/error domains should be taught in the curriculum. ( Separate Courses, - Within Selected Courses, Longitudinal) $\mathrm{N}=39$.

curriculum. The topics were mostly covered in the required, classroom-based part of the curriculum. ${ }^{20,21}$ More than half of the respondents indicated that all medication error domains and types should be taught within selected courses in the pharmacy practice curriculum. Fewer preferred that they be taught longitudinally, and the least preferred option was teaching these topics in separate courses.

Third, all educators indicated that all medication error domains and types be covered and required in the curriculum, with the preferred professional years for teaching domains being 3 and 4 , and the preferred years for teaching types of errors being 1 through 4 . This may indicate that participants believe that medication error domains contain more specialized material that should be covered at higher levels in the curriculum. In a previous study, some respondents suggested making the science of safety (SoS) a separate, mandatory course. ${ }^{19}$
Variations in educators' medication safety knowledge and previous training by years of experience in pharmacy education and gender were noted. While, experience in pharmacy education is expected to have an impact on knowledge and training, the variations by gender could not be explained and thus, need further investigation.

Although the PharmD curriculum at KSAU includes robust IPPE and APPE courses and rotations in line with the Accreditation Council for Pharmacy Education (ACPE), an important prospect of this study is the potential role of nonpractice faculty members in medication safety education of PharmD students. Nonpractice courses and topic discussions can be used to introduce PharmD students to medication safety concepts and bridge the gap between pharmacy practice and nonpractice courses, including pharmaceutical sciences. An

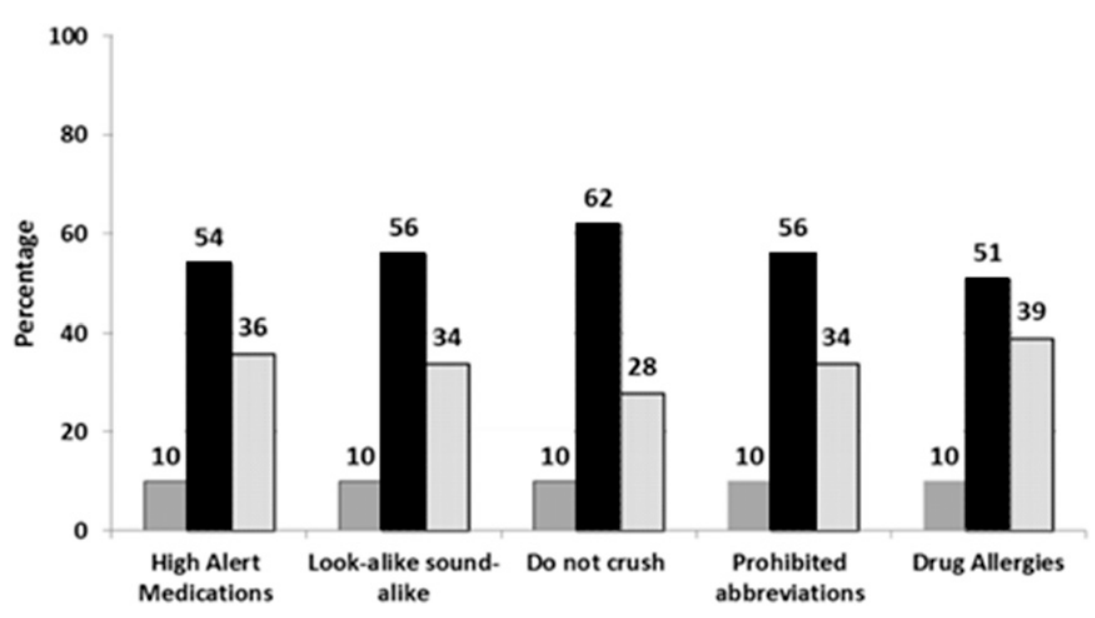

Figure 2. Percentage of respondents indicating how medication safety/error types should be taught in the curriculum. ( $\square$ Separate Courses, - Within Selected Courses, Longitudinal) $\mathrm{N}=39$. 


\section{American Journal of Pharmaceutical Education 2017; 81 (2) Article 30.}

interesting approach to medication safety education is the Educating Pharmacy Students to Improve Quality (EPIQ) curriculum, which is a modular educational stream that looks at medication error reduction from quality indicators and quality measurement approach. ${ }^{22}$ It could be useful to add topics related to quality improvement in nonpractice courses to some of EPIQ's modules or to imbed some of the existing modules in nonpractice courses. It is possible to include discussion in courses related to drug and formulation design to tackle problems like handling do-not-crush medications or look-alikesound-alike medication errors. On the other hand, courses in pharmacy management and pharmacoeconomics can be a suitable venue for the discussion of quality improvement as a tool to reduce medication safety. Another approach that seems to be solely used in practical settings is continuous quality improvement (CQI), which is a system approach to quality improvement that was used to reduce medication errors in the community pharmacy setting. ${ }^{23}$ Although such systematic approaches can be experienced in community and institutional IPPEs and APPEs, nonpractice courses can serve as an introductory platform for the concepts of CQI. Introductory pharmacy, pharmacy management, and pharmacoeconomics courses are suitable for such a purpose. We can even argue that the discussion of CQI concepts in pharmaceutical manufacturing can serve as a primer for the use of the same concepts in medication error reduction.

A direct approach to the integration of pharmaceutical science courses (eg, pharmaceutics with pharmacy practice) was introduced by Stewart and colleagues. ${ }^{24}$ Their approach of discussing a simulated case involving a medication safety issue related to an error in tonicity calculation and its impact on the patient's health was both direct and effective in linking a physical pharmacy concept to pharmacy practice.

A strength of this study is its use of a comprehensive questionnaire to measure overall and individual aspects of pharmacy educators' self-rated medication safety knowledge and perceptions about the importance of the domains and topics in the PharmD curriculum. Another important outcome of this study was its value regarding assessing the level of training and knowledge about medication safety among pharmacy educators at KSAU-HS College of Pharmacy and the opportunity to use the results to enhance the education of all faculty members on these important topics.

The primary limitation of this study was the small sample size and the unevenly dispersed study participants in terms of general discipline, academic degree, and rank. This was dictated by the number of available educators who participated in this survey. This limitation may have influenced the power of the study and thus the ability to explore and identify other potential variations in knowledge and perception between educators. Another limitation is the inability to generalize the findings to other PharmD programs around the world, though we believe using a similar questionnaire would reveal similar results at any college or school of pharmacy.

\section{CONCLUSION}

This study demonstrated significant variations in pharmacy educators' knowledge about medication safety and some differences in their perception toward how it should be integrated into the PharmD curriculum at KSAU-HS College of Pharmacy. These differences were observed by various demographic factors including general discipline, academic degree, years of experience in pharmacy education, and gender. While several studies have focused on the importance of medication safety in medical practice in the Middle East, this appears to be the first study that assessed pharmacy educators' knowledge and perceptions of integration of medication safety into pharmacy curriculum in this particular region. Most pharmacy faculty members who participated in this study seemed to acknowledge the importance of medication safety topics to the practice of pharmacy and believed they should be incorporated into the curriculum. The results of this study can set the stage for conducting further studies to evaluate the extent of coverage of these issues and guide curricular change regarding the incorporation of medication safety domains and topics in PharmD curricula when they are not currently covered in colleges locally, regionally, and internationally. We can argue that the education of medication safety concepts in the pharmaceutical sciences courses could be an important step toward bridging the academic gap between these sciences and pharmacy practice.

\section{REFERENCES}

1. Aspden P, Wolcott JA, Bootman JL, Cronenwett LR, Committee on Identifying and Preventing Medication Errors, Institute of Medicine, eds. Preventing Medication Errors. Washington, DC: National Academies Press; 2006.

2. Kohn LT, Corrigan JM, Donaldson MS, Committee on Quality of Health Care in America, Institute of Medicine, eds. To Err is Human: Building a Safer Health System. Washington, DC: National

Academies Press; 2000.

3. Budnitz DS, Lovegrove MC, Shehab N, Richards CL. Emergency hospitalizations for adverse drug events in older Americans. $N$ Engl $J$ Med. 2011;365(21):2002-2012.

4. Committee on Quality of Health Care in America, Institute of Medicine. Crossing the Quality Chasm: New Health System for the 21st Century. Washington, DC: National Academies Press; 2001. 5. Tregunno D, Ginsburg L, Clarke B, Norton P. Integrating patient safety into health professionals' curricula: a qualitative study of 


\section{American Journal of Pharmaceutical Education 2017; 81 (2) Article 30.}

medical, nursing and pharmacy faculty perspectives. BMJ Qual Saf. 2014;23(3):257-264.

6. WHO. WHO Patient Safety Curriculum Guide for Medical Schools. 2009. http://whqlibdoc.who.int/publications/2009/ 9789241598316_eng.pdf?ua $=1$.

7. Warholak TL, Noureldin M, West D, Holdford D. Faculty perceptions of the educating pharmacy students to improve quality (EPIQ) program. Am J Pharm Educ. 2011;75(8):Article 163. 8. Accreditation Council for Pharmacy Education (ACPE). Accreditation standards and key elements for the professional program in pharmacy leading to the doctor of pharmacy degree. Standards 2016.

9. Tang DH, Warholak TL, Slack MK, Malone DC, Gau C-S. Science of safety topic coverage in experiential education in US and Taiwan colleges and schools of pharmacy. Am J Pharm Educ. 2011;75(10):Article 202.

10. Kiersma ME, Plake KS, Darbishire PL. Patient safety instruction in US health professions education. Am J Pharm Educ. 2011;75(8): Article 162.

11. Johnson MS, Latif DA, Gordon B. Medication error instruction in schools of pharmacy curricula: a descriptive study. Am J Pharm Educ. 2002;66(4):364-371.

12. Al-Jeraisy MI, Alanazi MQ, Abolfotouh MA. Medication prescribing errors in a pediatric inpatient tertiary care setting in Saudi Arabia. BMC Res Notes. 2011;4(1):294.

13. Alsulami Z, Conroy S, Choonara I. Medication errors in the Middle East countries: a systematic review of the literature. Eur J Clin Pharmacol. 2013;69(4):995-1008.

14. Kheir N, Zaidan M, Younes H, El Hajj M, Wilbur K, Jewesson PJ. Pharmacy education and practice in 13 Middle Eastern countries. Am J Pharm Educ. 2008;72(6):Article 133.

15. Sabry NA, Farid SF, Aziz EOA. Role of the pharmacist in identification of medication related problems in the ICU: a preliminary screening study in an Egyptian teaching hospital. Austr J Basic Appl Sci. 2009;3(2):995-1003.

16. Frank JR, Brien S. The Safety Competencies: Enhancing Patient Safety Across the Health Professions. Ottawa, ON: Canadian Patient Safety Institute; 2008.

17. Emanuel L, Walton M, Hatlie M, et al. The patient safety education project: an international collaboration. In: Henriksen K, Battles JB, Keyes MA, Grady ML, eds. Advances in Patient Safety: New Directions and Alternative Approaches. Vol. 2: Culture and Redesign. Rockville, MD: Agency for Healthcare Research and Quality; 2008.

18. Walton MM, Shaw T, Barnet S, Ross J. Developing a national patient safety education framework for Australia. Qual Safe Health Care. 2006;15(6):437-442.

19. Warholak TL, Holdford DA, West D, et al. Perspectives on educating pharmacy students about the science of safety. Am J Pharm Educ. 2011;75(7):Article 142.

20. West-Strum D, Basak R, Bentley JP, et al. The science of safety curriculum in US Colleges and schools of pharmacy. Am J Pharm Educ. 2011;75(7):Article 141

21. Holdford DA, Warholak TL, West-Strum D, Bentley JP, Malone DC, Murphy JE. Teaching the science of safety in US Colleges and schools of pharmacy. Am J Pharm Educ. 2011;75(4):Article 77. 22. Gilligan AM, Myers J, Nash JD, et al. Educating pharmacy students to improve quality (EPIQ) in colleges and schools of pharmacy. Am J Pharm Educ. 2012;76(6):Article 109. 23. Boyle TA, Bishop AC, Duggan K, et al. Keeping the "continuous" in continuous quality improvement: Exploring perceived outcomes of CQI program use in community pharmacy. Res Social Adm Pharm. 2014;10(1):45-57.

24. Stewart AL, Buckner IS, Wildfong PL. A shared assignment to integrate pharmaceutics and pharmacy practice course concepts. Am J Pharm Educ. 2011;75(3):Article 44. 